\title{
Time Variability of the Foliated Fixed Wireless Access Channel at $3.5 \mathrm{GHz}$
}

\author{
D. Crosby ${ }^{\dagger}$, V.S. Abhayawardhana*, I.J. Wassell** ${ }^{*}$, M. G. Brown ${ }^{\ddagger}$, M.P. Sellars ${ }^{\dagger}$ \\ $\nmid$ Cambridge Broadband Ltd., Selwyn House, Cowley Rd., Cambridge CB4 OWZ, UK. \\ \{dcrosby,msellars\}@ cambridgebroadband.com \\ *BT Mobility Research Unit, Rigel House, Adastral Park, Ipswich IP5 3RE, UK. \\ viraj.abhayawardhana@bt.com \\ $* *$ Laboratory for Communication Engineering, Dept. of Engineering, University of Cambridge, \\ Cambridge CB2 1PZ, UK. \\ ijw24@eng.cam.ac.uk \\ $\ddagger$ Cotares Ltd., 67, Narrow Lane, Histon, Cambridge CB4 9YP, UK. \\ mgbrown@cotares.com
}

\begin{abstract}
This paper examines the temporal characteristics of the fixed wireless access channel resulting from the combined effects of foliage and wind. Measurements at a frequency of $3.5 \mathrm{GHz}$ taken over the course of one year are presented. The temporal variability of the path loss is shown to be well approximated by a Rician process. The dependency of the median $K$ factor on excess path loss, average wind speed and season is investigated. An empirical expression for the median $K$ factor encompassing these variables is presented. The median $K$ factor is found to be approximately inversely proportional to average wind speed.
\end{abstract}

\section{INTRODUCTION}

Fixed Wireless Access (FWA) systems typically use a point to multipoint architecture where a Base Station (BS) supports multiple Customer Premises Equipments (CPEs). The antennas employed by the CPE are usually highly directional (beamwidths of $10^{\circ}$ to $20^{\circ}$ are typical at $3.5 \mathrm{GHz}$ ) and mounted at rooftop level. To maximise system coverage, propagation conditions are often Non-Line-Of-Sight (NLOS) with the signal undergoing multiple scattering from buildings, trees and other topographic obstacles. NLOS propagation conditions are particularly sensitive to any movement of the scattering objects, resulting in temporal variation of received signal strength and affecting system outage probability. It is essential to have a thorough understanding of the time variability of the FWA channel in order to offer a service reliability comparable to that of wireline networks.

Time variability of FWA links have been examined in [1][2][3]. These studies assume a Rician approximation for the received signal amplitude and present measurements of the Rician K factor. In [1] an expression for the median K factor was determined empirically as a function of season, antenna height, antenna beamwidth and distance. The median $\mathrm{K}$ factor decreases with distance and improves by a factor of 2.5 when moving from summer (more leaves) to winter (less leaves). The expression agrees well with other measurements [4][5].
While the previous studies have identified wind, and particularly the movement of foliage, as having a significant impact on signal fading, these factors have not been examined comprehensively in actual deployments and over long time scales. The studies of [6][7][8] and [9] have addressed the combined effects of wind and foliage for a small number of links over relatively small transmission distances. The study in [6] considered three foliated channels featuring two to four trees and with distances of up to $110 \mathrm{~m}$. The transmitted signal consisted of four tones (one for each of the frequencies studied) and the received signal power was monitored at each frequency for a period of 45 days. Four categories of wind velocity ranging from low to high were analysed. The variation in received power was found to be strongly dependent on the wind velocity. In [7] and [8] the statistics of the received signal for a single moving tree were examined in the controlled conditions of an anechoic chamber. Wind velocity was found to have almost no effect on the standard deviation of the received signal level in [7], and in [8], the Rician $\mathrm{K}$ factor was found to vary exponentially with wind speed at frequencies of 12 and $17 \mathrm{GHz}$.

This paper presents and analyses measurements of the time variability from wind and foliage in a deployed urban FWA system. A total of $36 \mathrm{CPEs}$ with link distances of up to $17 \mathrm{~km}$ were observed continually over a 12 month period in order to investigate the relationship between Rician $\mathrm{K}$ factor, wind speed, season and excess path loss.

The sections of this paper are organised as follows. Section II provides a brief description of the FWA system, measurements and the data processing. Section III presents the results of the K factor analysis. Section IV concludes this paper.

\section{Measurements}

FWA networks in the UK have been allocated spectrum in the $3.5 \mathrm{GHz}$ band. As part of an investigation into spectral 
efficiency for this band ${ }^{1}$, a near-commercial scale broadband FWA network has been deployed in Cambridge, UK, and has provided an opportunity to investigate long term propagation aspects of the FWA channel.

Cambridge can be described as an urban centre of medium density with buildings typically two to three storeys high. The terrain is very flat and the predominantly deciduous trees provide medium foliage cover.

The deployed network consists of five BS sites, and some 65 CPEs and has been operational since June 2003. The CPE antennas have beamwidths of $15^{0}$ and are mounted at rooftop level (typically 5-10 metres above ground level). At installation, each CPE antenna was aligned to receive maximum signal power, and was fixed for the duration of the measurements.

Each of the BS sites employed four Access Points (AP) each having an antenna with beamwidths of $90^{\circ}$ and $7^{\circ}$ in azimuth and elevation respectively. Both AP and CPE antennas were right hand circularly polarised. The APs transmitted a 2.5 or $5 \mathrm{Msymbol} / \mathrm{s}$ QPSK modulated signal at a power of $16 \mathrm{dBW}$ EIRP.

The received signal powers from 36 CPEs in the network has been continually logged since the beginning of the project. These CPEs are located at distances ranging from $0.3 \mathrm{~km}$ to $17 \mathrm{~km}$. For each CPE the received power is recorded at intervals of one second, and stored in a central database for post-processing. The database record exceeds one year and covers all four seasons.

In this study, post-processing involved segmenting the database record for each CPE into sequences 30 minutes in length (1800 samples). The following statistics were then calculated for every data sequence:

- median path loss

- Rician K factor of the fluctuations of the received power

- frequency histogram of the received power

- average wind speed over the duration of the data sequence

The Rician $\mathrm{K}$ factors were calculated according to the method proposed in [10]. A bin size of $0.5 \mathrm{~dB}$ was used for determining the frequency histogram. The average wind speed readings were obtained from a weather station colocated with one of the BS sites in Cambridge. This weather station recorded numerous parameters, including temperature and average wind speed, at 30 minute intervals.

\section{RESULTS}

\section{A. Time variability of a typical CPE}

A link having a CPE to AP antenna separation of approximately $3 \mathrm{~km}$ was selected for detailed investigation since it demonstrated performance typical of the majority of links in the network. The AP and CPE antennas were some $30 \mathrm{~m}$ and $8 \mathrm{~m}$ above ground level respectively. The propagation path was NLOS owing to obstruction by numerous trees and buildings along the link.

A plot of received power sampled at intervals of one second taken over a two day period for the selected CPE (User 1) is shown in Figure 1-a. The received power is highly nonstationary and exhibits fading depths in excess of $10 \mathrm{~dB}$. Close correspondence is observed between the variability of the received power and the average wind velocity over the same period (Figure1-b). Figure 1 suggests that the dominant fading mechanism for this user is the movement of foliage owing to wind. The time variability of all user links were similarly found to be affected by wind velocity.

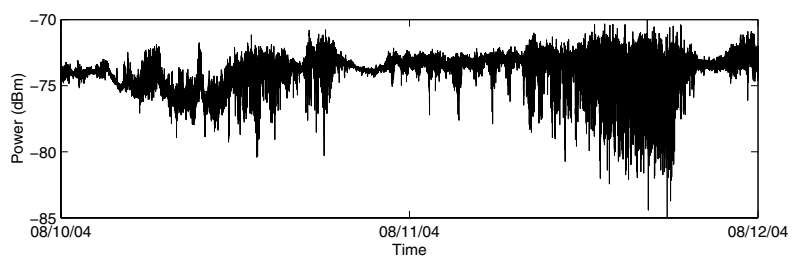

(a)

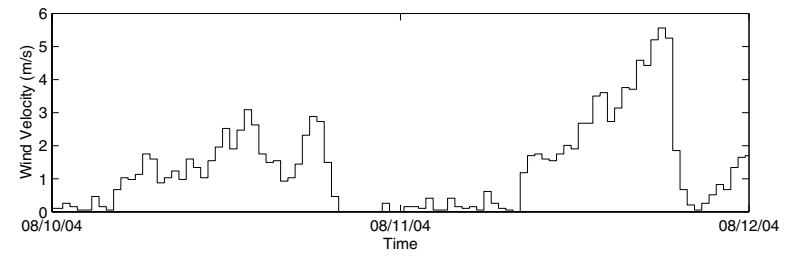

(b)

Fig. 1. Typical signal power and wind speeds (User 1).

\section{B. Distribution of signal amplitude}

When analysing the time variability of FWA systems a Rician model is typically assumed [1][2][3]. That is, the signal arriving at the CPE is modelled as being the sum of a fixed plus a fluctuating (scatter) component. However, for the specific case of wind and foliage, [6] and [11] have found good agreement with a Lognormal distribution.

In order to determine the most applicable model the observed samples were compared to both Rician and Lognormal distributions. To ensure a meaningful comparison, all 30 minute sequences were first checked to identify those with significant fading (defined as those with a standard deviation of signal fluctuations greater than $2 \mathrm{~dB}$ ). This located 10758 sequences, and for each of these the Kolmogrov-Smirnov test (significance level of 0.05 ) was used to compare the observed cumulative distribution function (CDF) against Rician and Lognormal CDFs [12]. The Rician distribution passed $90 \%$ of the tests while the Lognormal distribution passed $54 \%$. The measurements gathered in this trial, therefore, suggest the most representative distribution is Rician. For the remainder of this paper the variability of the received amplitude is quantified in terms of the Rician $\mathrm{K}$ factor.

\section{C. $K$ factor analysis for User 1}

The $\mathrm{K}$ factor data for each CPE was analysed season by season. For each season $S$, the K factor data was sorted into

1. The authors wish to thank the UK telecommunication regulator, Ofcom, for sponsoring the project. 
ten groups according to average wind speed. These groups corresponded to a nominal average wind speed of $\bar{w}=$ $[1,2, \ldots, 10] \mathrm{m} / \mathrm{s}$. A $\mathrm{K}$ factor sample was allocated to a wind speed category $\bar{w}$ if the average wind speed for that sample fell within the bounds $[\bar{w}-0.5, \bar{w}+0.5) \mathrm{m} / \mathrm{s}$. Once all the $\mathrm{K}$ factors had been allocated in this way, the median of each group was then calculated, resulting in values of $K^{m}(S, \bar{w})$, representing the median $\mathrm{K}$ factor for a given $\mathrm{CPE}$ in season $S$ and an average wind speed of $\bar{w}=[1, \ldots, 10] \mathrm{m} / \mathrm{s}$.

For example, Figure 2 shows $\mathrm{K}$ factor against the average wind speed for User 1 (suburban environment). The $\mathrm{K}$ factor data is plotted as small dots, whereas the localised medians $K^{m}(S, \bar{w})$ are shown as solid lines. Significant spread is observed around the median and may be attributed to a number of sources, such as variation in wind direction, the low sample rate of the wind speed data, the fact that the wind speed is measured at a location distant to the CPE, traffic, and other environmental factors. However, the median curves for all seasons clearly show a strong relationship between $\mathrm{K}$ factor and average wind speed. Indeed the curves have a similar slope. Seasonal differences are also evident and close to an order of magnitude improvement in the median $\mathrm{K}$ factor can be seen when moving from summer/autumn to winter/spring. This is due to the presence of deciduous trees along the link and the relative lack of leaves in winter and spring. The curves for summer and autumn have almost identical characteristics, as have those for winter and spring. This may be explained by the similarity of foliage cover during these seasons.

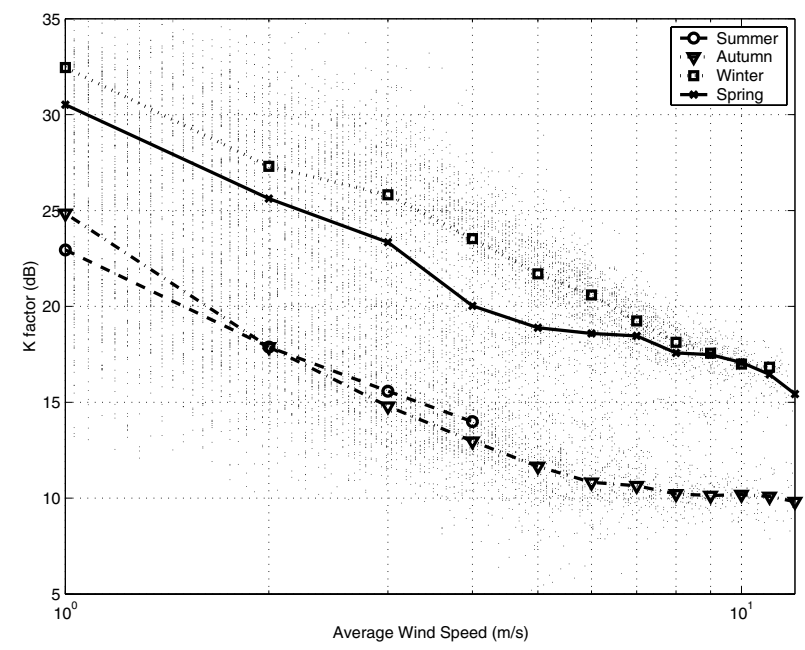

Fig. 2. Seasonal variation of $\mathrm{K}$ factor vs. average wind speed for a typical $\mathrm{CPE}$. The lines are the median $\mathrm{K}$ factors, $K^{m}(S, \bar{w})$.

Similar trends to those shown in Figure 2 were observed for all CPEs in the project, although seasonal variations were found to depend upon the nature of the foliage along each link. For example, those CPEs shadowed by mostly non-deciduous trees experienced less variation in the median $\mathrm{K}$ factor from season to season.

\begin{tabular}{|c|c|c|c|c|c|c|c|c|}
\hline \multirow{2}{*}{$\begin{array}{l}\bar{w} \\
(\mathrm{~m} / \mathrm{s})\end{array}$} & \multicolumn{2}{|c|}{ Summer } & \multicolumn{2}{|c|}{ Autumn } & \multicolumn{2}{|c|}{ Winter } & \multicolumn{2}{|c|}{ Spring } \\
\hline & $\begin{array}{l}C_{0} \\
(\mathrm{~dB})\end{array}$ & $C_{1}$ & $\begin{array}{l}C_{0} \\
(\mathrm{~dB})\end{array}$ & $C_{1}$ & $\begin{array}{l}C_{0} \\
(\mathrm{~dB})\end{array}$ & $C_{1}$ & $\begin{array}{l}C_{0} \\
(\mathrm{~dB})\end{array}$ & $C_{1}$ \\
\hline 1.0 & 37.9 & -0.44 & 38.3 & -0.42 & 41.8 & -0.42 & 42.0 & -0.45 \\
\hline 2.0 & 32.4 & -0.45 & 33.9 & -0.45 & 38.4 & -0.48 & 39.2 & -0.56 \\
\hline 3.0 & 29.7 & -0.43 & 31.9 & -0.44 & 36.9 & -0.49 & 36.8 & -0.55 \\
\hline 4.0 & 30.1 & -0.52 & 30.1 & -0.44 & 34.9 & -0.48 & 34.8 & -0.55 \\
\hline 5.0 & 30.3 & -0.58 & 28.9 & -0.43 & 34.0 & -0.51 & 33.6 & -0.56 \\
\hline 6.0 & & & 27.9 & -0.43 & 33.2 & -0.51 & 33.2 & -0.56 \\
\hline 7.0 & & & 27.9 & -0.47 & 32.3 & -0.52 & 33.2 & -0.57 \\
\hline 8.0 & & & 27.3 & -0.47 & 31.2 & -0.51 & 32.6 & -0.57 \\
\hline 9.0 & & & 27.4 & -0.49 & 30.1 & -0.47 & 31.5 & -0.56 \\
\hline 10.0 & & & 26.8 & -0.49 & 29.2 & -0.47 & 30.7 & -0.56 \\
\hline
\end{tabular}

TABLE I

REGRESSION COEFFICIENTS FOR (2) AND WIND SPEEDS OF 1-10 M/S

\section{Correlation of the median $K$ factor with excess path loss}

Other studies have noted a correlation between $\mathrm{K}$ factor and excess loss [13]. To investigate this, samples of received power for each CPE were first processed to produce a median path loss, $L(S)$ for each AP to CPE link for a given season. A seasonal value of the median excess loss, $A(S)$ was then determined for each CPE according to:

$$
A(S)=L(S) / L_{f s}
$$

where $L_{f s}=(4 \pi d / \lambda)^{2}$ is the free space path loss, $\lambda$ is the wavelength, and $d$ is the AP to CPE separation.

It was then possible to examine the dependencies of the median $\mathrm{K}$ factor on wind speed and excess path loss for each season. Figure 3 shows an example of the results at an average wind speed of $\bar{w}=3 \mathrm{~m} / \mathrm{s}$ for all seasons. A regression curve of the form given in (2) is also shown as a solid line.

$$
K^{m}(S, \bar{w})=C_{0} A(S)^{C_{1}}
$$

The median $\mathrm{K}$ factor clearly decreases with the median excess path loss and the slopes of the regression are similar for all four seasons $\left(C_{1} \approx-0.5\right)$. Summer and autumn have a median $\mathrm{K}$ factor that is lower than winter and spring. The observed correlation between median $\mathrm{K}$ factor and median excess loss suggests that for this environment, median excess loss is an indicator of foliage obstruction on the fixed or scattered paths. Unlike other studies [1][4], a high correlation between $\mathrm{K}$ factor and distance was not found.

Table I lists the regression coefficients for all ten wind speed categories. The standard deviation about the regression curve is less than $3.6 \mathrm{~dB}$ for all wind speeds analysed. The missing entries for summer are a result of insufficient data due to the much lower wind speed during this season. $C_{1}$ is relatively invariant with wind speed, while $C_{0}$ changes by over $10 \mathrm{~dB}$.

\section{E. Empirical expression for the median $K$ factor}

In order to obtain an empirical expression for the median $\mathrm{K}$ factor, it is necessary to modify (2) to include an average wind speed term. The results of Figure 2 suggest that, to a first approximation, $K^{m}(S, \bar{w})$ is essentially inversely proportional 


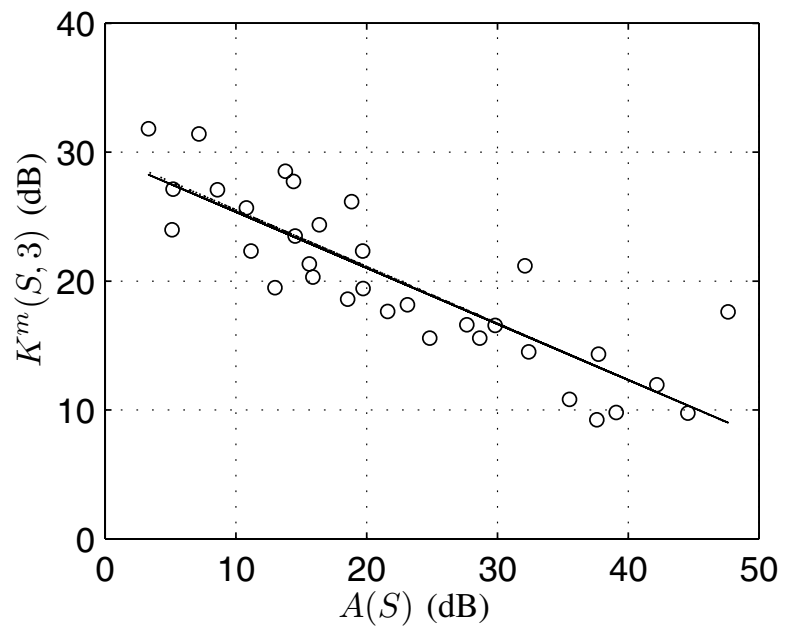

(a)

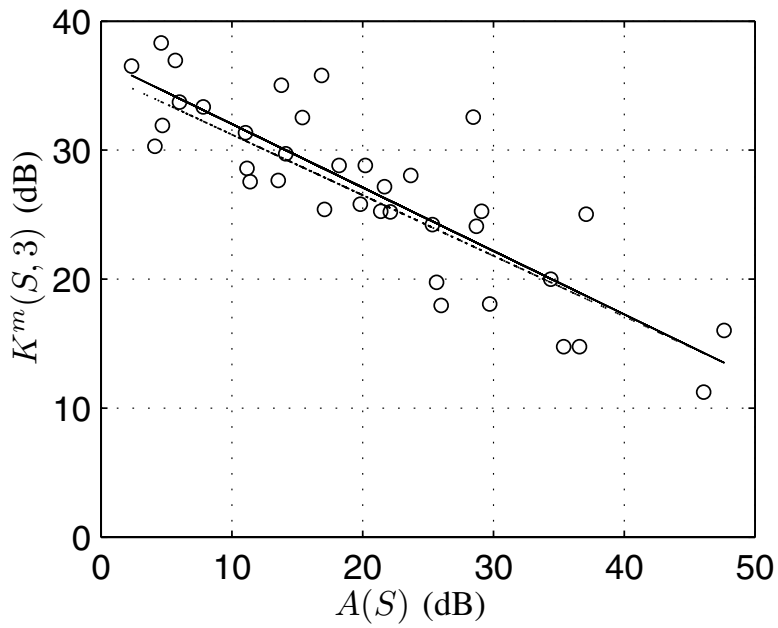

(c)

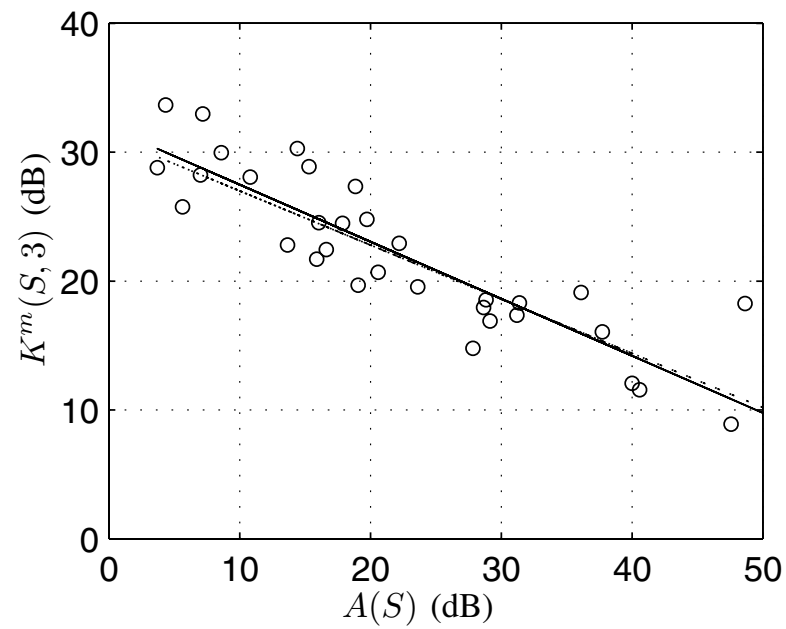

(b)

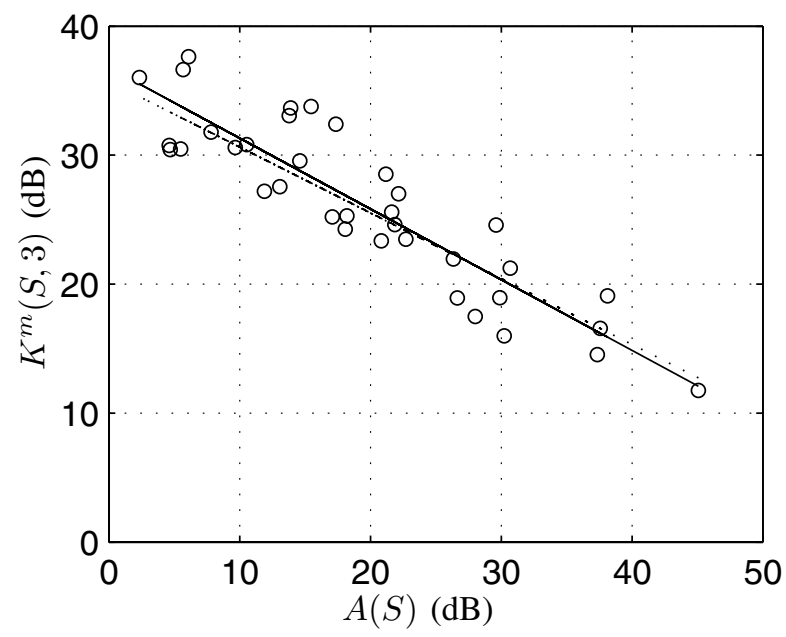

(d)

Fig. 3. Median K factor vs. median excess path loss for an average wind speed of $\bar{w}=3 \mathrm{~m} / \mathrm{s}$ and for (a) summer, (b) autumn, (c) winter and (d) spring. The solid and dotted lines are the regression curves of (2) and (3) respectively.

to $\bar{w}^{n}$. Indeed, when the regression coefficient $C_{0}$ is plotted against $\bar{w}$ (Figure 4) a similar dependency is observed, and $C_{0}$ is seen to vary at close to $-15 \mathrm{~dB} /$ decade (i.e. $n \approx 1.5$ ). Therefore the following expression for the median $\mathrm{K}$ factor as a function of median excess path loss and average wind speed is proposed:

$$
K^{m}(S, \bar{w})=\frac{D_{0} A(S)^{D_{1}}}{\bar{w}^{D_{2}}}
$$

Table II lists the coefficients obtained from a regression fit for (3). The standard deviation about the regression curve is less than $3.5 \mathrm{~dB}$ for all seasons. Equation (3) predicts that the median $\mathrm{K}$ factor is approximately inversely proportional to average wind speed and, as expected, becomes infinite at $0 \mathrm{~m} / \mathrm{s}$. For comparison, (3) is plotted as a dotted line in Figure 3 for $\bar{w}=3$. The values of $D_{0}$ show that winter has a median $\mathrm{K}$ that is approximately 3.2 times that of summer, a value that is reasonably close to the figure of 2.5 reported in [1].

To illustrate the dependencies in (3), Figure 5 plots the variation in median $\mathrm{K}$ factor for a range of average wind speeds and median excess path losses for the summer season. The median $\mathrm{K}$ factor is sensitive to change in either median path loss or average wind speed. The circles on this Figure are the measurements of the $\mathrm{K}$ factor from [8]. The similarity of the results of [8] and that predicted by (3) are notable given that the measurements of [8] were obtained for a higher frequency $(12 \mathrm{GHz})$ and for a single tree in anechoic conditions at constant wind velocity. 


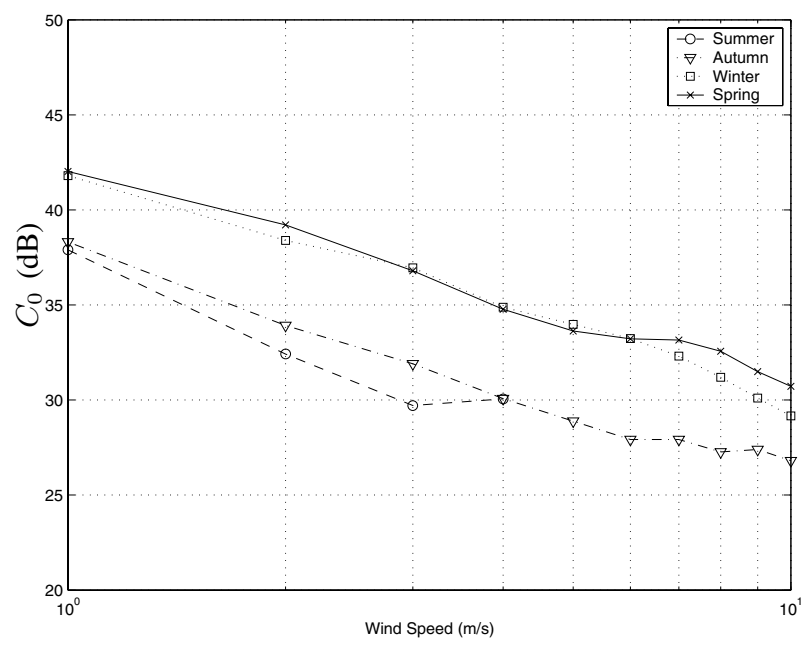

Fig. 4. Variation in the regression coefficient $C_{0}$ with average wind speed.

\begin{tabular}{|l|l|l|l|}
\hline Season & $D_{0}(d B)$ & $D_{1}$ & $D_{2}$ \\
\hline \hline Summer & 38.01 & -0.47 & 1.51 \\
Autumn & 38.34 & -0.45 & 1.27 \\
Winter & 43.00 & -0.48 & 1.34 \\
Spring & 43.23 & -0.55 & 1.29 \\
\hline
\end{tabular}

TABLE II

REGRESSION COEFFICIENTS FOR (3)

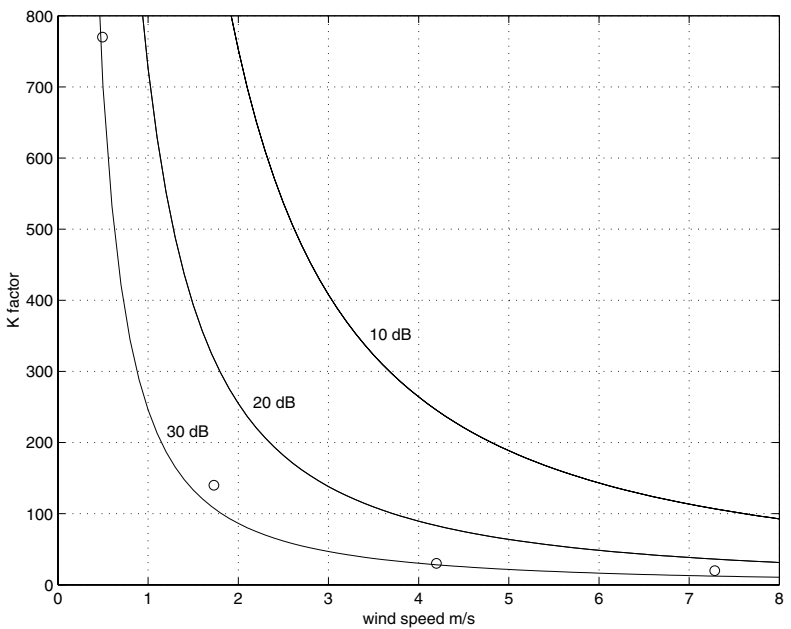

Fig. 5. Plot of (3) for median excess path losses of 10, 20 and $30 \mathrm{~dB}$ (summer). The circles are from [8].

\section{CONCLUSION}

Measurements for the time variability of $36 \mathrm{CPEs}$ in a deployed FWA network were analysed for a period of more than one year. An empirical expression relating the median $\mathrm{K}$ factor to median excess loss, average wind speed and season has been presented. The $\mathrm{K}$ factor in winter was approximately 3.2 times higher than in summer.

\section{REFERENCES}

[1] L. Greenstein, S. Ghassemzadeh, V. Erceg, and D. Michelson, "Ricean $\mathrm{K}$-factors in narrowband fixed wireless channels," in Proceedings of the International Conference on Wireless Personal Multimedia Communications, vol. 1, September 1999.

[2] D. Baum, D. Gore, R. Nabar, S. Panchanathan, K. Hari, V. Erceg, and A. Paulraj, "Measurement and characterization of broadband MIMO fixed wireless channels at $2.5 \mathrm{GHz}$," in Proc. of IEEE ICPWC'O0, pp. 203-206, December 2000.

[3] M. J. Gans, N. Amitay, et al., "Propagation measurements for fixed wireless loops (FWL) in a suburban region with foliage and terrain blockages," IEEE Transactions on Wireless Communication, vol. 1, pp. 302-310, April 2002.

[4] V. Erceg, P. Soma, D. Baum, and S. Catreux, "Multiple-input multipleoutput fixed wireless radio channel measurements and modeling using dual-polarised antennas at $2.5 \mathrm{GHz}$," IEEE Transactions on Wireless Communications, vol. 3, pp. 2288-2296, November 2004.

[5] H. Bolcskei, A. Paulraj, K. Hari, R. Nabar, and W. Lu, "Fixed broadband wireless access: State of the art, challenges and future directions," in IEEE Communications Magazine, vol. 1, pp. 100-108, January 2001.

[6] S. Perras and L. Bouchard, "Fading characteristics of RF signals due to foliage in frequency bands from 2 to $60 \mathrm{GHz}$," in Proceedings of the International Symposium on Wireless Personal Multimedia Communications, vol. 1, pp. 267-271, October 2002.

[7] A. Kajiwara, "Foliage attenuation characteristics for LMDS radio channel," IEICE Transactions on Communications, vol. E83-B, pp. 21302134, September 2000.

[8] M. Hashim and S. Stavrou, "Dynamic impact characteristation of vegetation movements on radiowave propagation in controlled environment," IEEE Antennas and Wireless Propagation Letters, vol. 2, pp. 316-317, 2003.

[9] E. Pelet, J. Salt, and G. Wells, "Effect of wind and foliage obstructed line-of-sight channel at $2.5 \mathrm{GHz}$," IEEE Transactions on Broadcasting, vol. 50, pp. 224-232, September 2004.

[10] A. Abidi, C. Tepedelenlioglu, M. Kaveh, and G. Giannakis, "On the estimation of the $\mathrm{K}$ parameter for the rice fading distribution," IEEE Communication Letters, vol. 5, pp. 92-94, March 2001.

[11] B. Benzair, H. Smith, and J. Norbury, "Tree attenuation measurements at 1-4 GHz for mobile radio systems," in Proceedings of the International Conference on Mobile Radio and Personal Communication, pp. 16-20, December 1991.

[12] N. Naz and D. Falconer, "Temporal variations characterization for fixed wireless at $29.5 \mathrm{GHz}$," in VTC, 2000.

[13] P. Papazian, G. Hufford, R. Achatz, and R. Hoffman, "Study of local multipoint distribution service radio channel," IEEE Transactions on Broadcasting, vol. 43, pp. 1-10, June 1997. 